\title{
Analysis of Training Load Perception of Young Soccer Players Based on Some Variables
}

\author{
Kamil Erdem (Corresponding author) \\ Faculty of Sport Science, Marmara University, İstanbul, Turkey \\ Tel: 90-532-733-6604 E-mail: kerdem@marmara.edu.tr \\ Recep Fatih Kayhan \\ School of Physical Education and Sports \\ Recep Tayyip Erdogan University, Rize, Turkey \\ Tel: 90-506-446-8009 E-mail: recepfatih.kayhan@erdogan.edu.tr
}

Received: January 14, 2020 Accepted: February 18, 2020 Published: February 25, 2020

doi:10.5296/jei.v6i1.16249 URL: https://doi.org/10.5296/jei.v6i1.16249

\begin{abstract}
The aim of this study is to examine the perception of training load of young soccer players during a five-week preparation period, based on their positions of play, $\mathrm{VO}_{2}$ max and years licensed and to compare the perceptions of the players with the training load planned by their coach. 17 young soccer players of Beşiktaş Football Club's U16 team who participated in the pre-season training prior to the 2018-2019 season volunteered to participate in this study. The height of the players is $175.38 \pm 4.83 \mathrm{~cm}$, body weight is $64.24 \pm 4.59 \mathrm{~kg}$, body mass index is $20.91 \pm 1.54 \mathrm{~kg} / \mathrm{m} 2$ and body fat percentage is $8.45 \pm 3.39$. During the 5 -week preparation period, the players assessed the rate of perceived exertion of the sections of each training session by using the Borg Scale, on a scale from 1 to10. The SPSS package program (SPSS 24) was used for statistical analysis of the research data. The Shapiro-Wilk test was used to assess normality and Levene's test was used to assess homogeneity. It was determined that the data distribution was normal. An independent t-test was implemented for comparison of the two groups, and a one-way ANOVA test was implemented for the comparison of multiple groups. The statistical results were evaluated at $\mathrm{p}<0.05$ significance level. As a result, the players' $\mathrm{VO}_{2}$ max values and the years of licensed soccer play may have an influence on their perception of the training load. The coaches' and young soccer players' perception levels of preparation period training load are compatible.
\end{abstract}


Keywords: Football, Soccer, Rate of perceived exertion, Player, Coach, RPE

\section{Introduction}

In order to prevent injuries in performance sports and to keep the performance high during the season, the training level of the athletes should be optimal. This requires the monitoring of the training load. Some methods have been developed by the researchers in order to track and monitor the training load. The training load is evaluated under two headings: internal and external load. The internal load refers to the physiological load that builds on the athlete during training.

It is the condition of the internal load that largely determines the compliance with the training program. The heart rate (HR), the rate of perceived exertion (RPE) and the lactate measurements can be given as examples for the internal load measurements (McGuigan, 2017). Although the most common measurement method is the heart rate, this method is costly due to the necessary equipment. Therefore, it is suggested to use the S-RPE method (Session Rating of Perceived Exertion) developed by Foster et al. (1995), as it is both cost-effective and valid (Rodriguez-Marroyo \& Antonan, 2015).

The S-RPE is obtained using a modified BORG category ratio (0-10). Although HR-based measurements and RPE-based measurements do not support each other, it is stated that the RPE method can be a better method for determining internal loads, and it can be an indicator of psychological stress besides physiological stress. Furthermore, it is stated that heart rate cannot be a good indicator of determining exercise intensity under certain conditions, such as cognitive demands, motivation status and intermittent nature of soccer training (Rodriguez-Marroyo \& Antonan, 2015). In one study, it was stated that there is a relationship between the percentage of HR reserve and the S-RPE measurements performed during 30-minute continuous and intermittent training at different intensities (Foster et al., 1995). In another study conducted with young soccer players, it is indicated that there is a significant correlation between HR responses and RPE responses (Impellizzeri et al., 2004). In a study conducted with young male taekwondo athletes, it was indicated that there is a weak correlation between the RPE and HR responses during high-intensity exercises (Haddad et al., 2011).

The S-RPE method can be a very practical and useful method for coaches to create periodization strategies, and to control and monitor internal load (Impellizzeri et al., 2004). Training load (TL), expressed in arbitrary units (AU), is calculated by multiplying the RPE value by the duration of the session, and is credited as a practical, cost-effective and valid method to measure the amount of internal training load in soccer (Impellizzeri et al., 2004).

When the literature is examined, the number of studies in which the young elite Turkish soccer players' perception of training load is determined is quite low. In this context, our study has importance. The aim of this study is to examine the perception of training load of young soccer players during the five-week preparation period based on their positions, $\mathrm{VO}_{2}$ max and years licensed, and to compare the players' perceptions of the training load planned by their coach. 


\section{Macrothink}

\section{Method}

\subsection{Research Group}

Seventeen young soccer players of Beşiktaş Football Club's U16 team who participated in the pre-season training prior to the 2018-2019 season volunteered to participate in this research.

\subsection{Anthropometric Measurements}

The height was taken with a stadiometer when the athlete was in anatomical posture, at the inspiration stage, with the head in the frontal plane and touching the vertex point. The body weight was taken with the athlete in anatomical posture on the scale without sportswear and shoes.

Skinfold thicknesses were measured, as suggested by Harrisson et al. (1988), in 7 areas (Biceps, Triceps, Subscapula, Suprailiac I, Suprailiac II, Abdominal and Calf) with a skinfold caliper (Holtain, England); circumference (Biceps, Biceps in Flexion, Wrist and Calf) and diameter (Humerus and Femurepicondyl) measurements were taken twice by the same person from the right side of the body with a Harpandenkaliper (Holtain, England) and the averages of these values were used in the calculations.

\subsection{Training Process}

For the season preparation, the soccer players were put through an adaptation training program of 3 days a week for 2 weeks, followed by a training program of 4-5 days a week for 5 weeks.

\subsection{Borg Scale}

During the 5-week preparation period, the players assessed the rate of perceived exertion of the sections of each training session by using the Borg Scale, on a scale from 1 to 10 (Borg, 1982). After the exercises in the main part of each training session, the Borg scale was shown to the players, the degree of difficulty perceived by the players for the exercises was recorded and by multiplying this by the duration of exercises, the perception scores were calculated. The average difficulty perception scores of the daily, weekly and preparatory training sessions were determined by addition of the perceived scores of the training session.

\subsection{Data Analysis}

The Microsoft Excel 2010 software was used to classify and calculate the perception scores of the data obtained at the end of the study, and the SPSS Statistics software package (version 24) was used for the statistical analysis of these data. The Shapiro-Wilk test was used to assess normality and Levene's test was used to assess homogeneity. It was determined that the data distribution was normal, and an independent t-test was implemented for comparison of the two groups, while the one-way ANOVA test was implemented for the comparison of multiple groups. The statistical results were evaluated at $\mathrm{p}<0.05$ significance level. 


\section{Results}

Table 1. The physical characteristics of soccer players

\begin{tabular}{|l|l|l|l|}
\hline Variables & N & Mean & Std. \\
\hline Height $(\mathrm{cm})$ & 17 & 175.38 & 4.83 \\
\hline Body Weight $(\mathrm{kg})$ & 17 & 64.24 & 4.59 \\
\hline Body Mass Index $\left(\mathrm{kg} / \mathrm{m}^{2}\right)$ & 17 & 20.91 & 1.54 \\
\hline Body Fat Percentage $(\%)$ & 17 & 8.45 & 3.39 \\
\hline
\end{tabular}

Table 1 presents the descriptive information of the soccer players. The height of the players is $175.38 \pm 4.83 \mathrm{~cm}$, body weight is $64.24 \pm 4.59 \mathrm{~kg}$, body mass index is $20.91 \pm 1.54 \mathrm{~kg} / \mathrm{m}^{2}$ and body fat percentage is $8.45 \pm 3.39$.

Table 2. T test results: rating of perceived exertion of soccer players based on their positions

\begin{tabular}{|c|c|c|c|c|c|c|}
\hline Weeks & Position Group & $\mathbf{N}$ & Mean & Std. & $\mathbf{t}$ & $\mathbf{p}$ \\
\hline \multirow{2}{*}{ Avg. Load Perceived in Week 1} & Defense & 8.00 & 166.55 & $11 . .88$ & \multirow{2}{*}{-0.44} & \multirow{2}{*}{0.67} \\
\hline & Attack & 9.00 & 169.07 & 11.59 & & \\
\hline \multirow{2}{*}{ Avg. Load Perceived in Week 2} & Defense & 8.00 & 204.47 & 9.89 & \multirow{2}{*}{-0.93} & \multirow{2}{*}{0.36} \\
\hline & Attack & 9.00 & 210.64 & 16.28 & & \\
\hline \multirow{2}{*}{ Avg. Load Perceived in Week 3} & Defense & 8.00 & 262.13 & 16.55 & \multirow{2}{*}{-0.61} & \multirow{2}{*}{0.55} \\
\hline & Attack & 9.00 & 267.62 & 20.18 & & \\
\hline \multirow{2}{*}{ Avg. Load Perceived in Week 4} & Defense & 8.00 & 378.94 & 23.77 & \multirow{2}{*}{0.50} & \multirow{2}{*}{0.63} \\
\hline & Attack & 9.00 & 373.42 & $22 . .01$ & & \\
\hline \multirow{2}{*}{ Avg. Load Perceived in Week 5} & Defense & 8.00 & 310.88 & 32.34 & \multirow{2}{*}{1.11} & \multirow{2}{*}{0.29} \\
\hline & Attack & 9.00 & 295.29 & 25.39 & & \\
\hline \multirow{2}{*}{ Avg. Load Perceived in Prep. Period } & Defense & 8.00 & 274.15 & $12 . .72$ & \multirow{2}{*}{0.25} & \multirow{2}{*}{0.81} \\
\hline & Attack & 9.00 & 272.55 & 13.75 & & \\
\hline
\end{tabular}

Note. $\mathrm{p}<0.05$.

When the RPE values of the players were examined based on their positions, no difference was found in the perceptions of the defenders and attackers in comparison with the preparation week. When the data were examined, it was found that the RPE values of attackers in the first week $(169.07 \pm 11.88)$, second week $(210.64 \pm 16.28)$ and third week 
(267.62 \pm 20.18$)$ were higher than that of the defenders. However, it was found that the defense players' average perceptions of difficulty in the fourth week (378.94 \pm 23.77 ), fifth week $(310.88 \pm 32.34)$ and preparation period $(274.15 \pm 12.72)$ were higher than that of the attackers.

Table 3. ANOVA test results: players' rating of perceived exertion based on $\mathrm{VO}_{2}$ max values

\begin{tabular}{|c|c|c|c|c|c|c|c|}
\hline Weeks & $\mathrm{VO}_{2}$ Max Groups & $\mathbf{N}$ & Mean & Std. & $\mathbf{F}$ & $\mathbf{p}$ & Tukey \\
\hline \multirow{4}{*}{ Avg. Load Perceived in Week 1} & 50 or more & 7.00 & 160.91 & 8.45 & \multirow{4}{*}{3.254} & \multirow{4}{*}{0.069} & \\
\hline & Between 48-50 & 5.00 & 169.84 & 11.39 & & & \\
\hline & Below 48 & 5.00 & 175.68 & 10.94 & & & \\
\hline & Total & 17.00 & 167.88 & 11.43 & & & \\
\hline \multirow{4}{*}{ Avg. Load Perceived in Week 2} & 50 or more & 7.00 & 202.57 & 6.73 & \multirow{4}{*}{1.052} & \multirow{4}{*}{0.375} & \\
\hline & Between 48-50 & 5.00 & 208.70 & 18.23 & & & \\
\hline & Below 48 & 5.00 & 214.00 & 15.63 & & & \\
\hline & Total & 17.00 & 207.74 & 13.62 & & & \\
\hline \multirow{4}{*}{ Avg. Load Perceived in Week 3} & 50 or more & 7.00 & 253.03 & 12.05 & \multirow{4}{*}{3.811} & \multirow{4}{*}{0.048} & \multirow{4}{*}{$2>1$} \\
\hline & Between 48-50 & 5.00 & 277.36 & 19.52 & & & \\
\hline & Below 48 & 5.00 & 269.52 & 16.11 & & & \\
\hline & Total & 17.00 & 265.04 & 18.20 & & & \\
\hline \multirow{4}{*}{ Avg. Load Perceived in Week 4} & 50 or more & 7.00 & 367.43 & 21.72 & \multirow{4}{*}{1.277} & \multirow{4}{*}{0.309} & \\
\hline & Between $48-50$ & 5.00 & 376.10 & 16.62 & & & \\
\hline & Below 48 & 5.00 & 387.95 & 26.43 & & & \\
\hline & Total & 17.00 & 376.01 & 22.30 & & & \\
\hline \multirow{4}{*}{ Avg. Load Perceived in Week 5} & 50 or more & 7.00 & 297.26 & 37.53 & \multirow{4}{*}{1.029} & \multirow{4}{*}{0.383} & \\
\hline & Between 48-50 & 5.00 & 294.60 & 17.88 & & & \\
\hline & Below 48 & 5.00 & 318.16 & 22.61 & & & \\
\hline & Total & 17.00 & 302.62 & 29.05 & & & \\
\hline \multirow{4}{*}{ Avg. Load Perceived in Prep. Period } & 50 or more & 7.00 & 265.27 & 13.57 & \multirow{4}{*}{3.763} & \multirow{4}{*}{0.049} & \multirow{4}{*}{$3>1$} \\
\hline & Between 48-50 & 5.00 & 274.92 & 2.86 & & & \\
\hline & Below 48 & 5.00 & 282.94 & 12.13 & & & \\
\hline & Total & 17.00 & 273.30 & 12.88 & & & \\
\hline
\end{tabular}

Note. $\mathrm{p}<0.05$.

In Table 3, when the RPE values of the players based on the $\mathrm{VO}_{2}$ max values were examined, among the perceived mean scores of the third week, a significant difference was found 


\section{Macrothink}

between the group having the $\mathrm{VO}_{2}$ max value of " $48-50 \mathrm{ml} / \mathrm{kg} / \mathrm{min}$ " and the group having the $\mathrm{VO}_{2}$ max value of "50 and above" at the $\mathrm{p}<0.048$ level, in favor of the group with a $\mathrm{VO}_{2}$ max value of $48-50 \mathrm{ml} / \mathrm{kg} / \mathrm{min}$.

Table 4. ANOVA test results: rating of perceived exertion of soccer players based on the licensed years variable

\begin{tabular}{|c|c|c|c|c|c|c|}
\hline Weeks & Years Licensed & $\mathbf{N}$ & Mean & Std. & $\mathbf{t}$ & $\mathbf{p}$ \\
\hline \multirow{2}{*}{ Avg. Load Perceived in Week 1} & 5 years & 7.00 & 174.29 & 9.80 & \multirow{2}{*}{2.14} & \multirow{2}{*}{0.05} \\
\hline & 6 years & 10.00 & 163.40 & 10.68 & & \\
\hline \multirow{2}{*}{ Avg. Load Perceived in Week 2} & 5 years & 7.00 & 213.96 & 14.84 & \multirow{2}{*}{1.66} & \multirow{2}{*}{0.14} \\
\hline & 6 years & 10.00 & 203.38 & 11.46 & & \\
\hline \multirow{2}{*}{ Avg. Load Perceived in Week 3} & 5 years & 7.00 & 269.46 & 13.29 & \multirow{2}{*}{0.83} & \multirow{2}{*}{0.38} \\
\hline & 6 years & 10.00 & 261.94 & 21.11 & & \\
\hline \multirow{2}{*}{ Avg. Load Perceived in Week 4} & 5 years & 7.00 & 378.00 & 30.29 & \multirow{2}{*}{0.30} & \multirow{2}{*}{0.80} \\
\hline & 6 years & 10.00 & 374.63 & 16.35 & & \\
\hline \multirow{2}{*}{ Avg. Load Perceived in Week 5} & 5 years & 7.00 & 319.63 & 25.16 & \multirow{2}{*}{2.27} & \multirow{2}{*}{0.04} \\
\hline & 6 years & 10.00 & 290.72 & 26.38 & & \\
\hline \multirow{2}{*}{ Avg. Load Perceived in Prep. Period } & 5 years & 7.00 & 281.12 & 10.38 & \multirow{2}{*}{2.38} & \multirow{2}{*}{0.03} \\
\hline & 6 years & 10.00 & 267.83 & 11.93 & & \\
\hline
\end{tabular}

Note. $\mathrm{p}<0.05$.

When the t-test results of the players based on the licensed years variable in Table 4 were examined, a significant difference was detected between the 5-year and 6-year licensed players' first week perceptions at $p<0.05$ level, the fifth week perceptions at $p<0.04$ level and the preparation period perceptions at $\mathrm{p}<0.03$ level. 


\section{Macrothink}

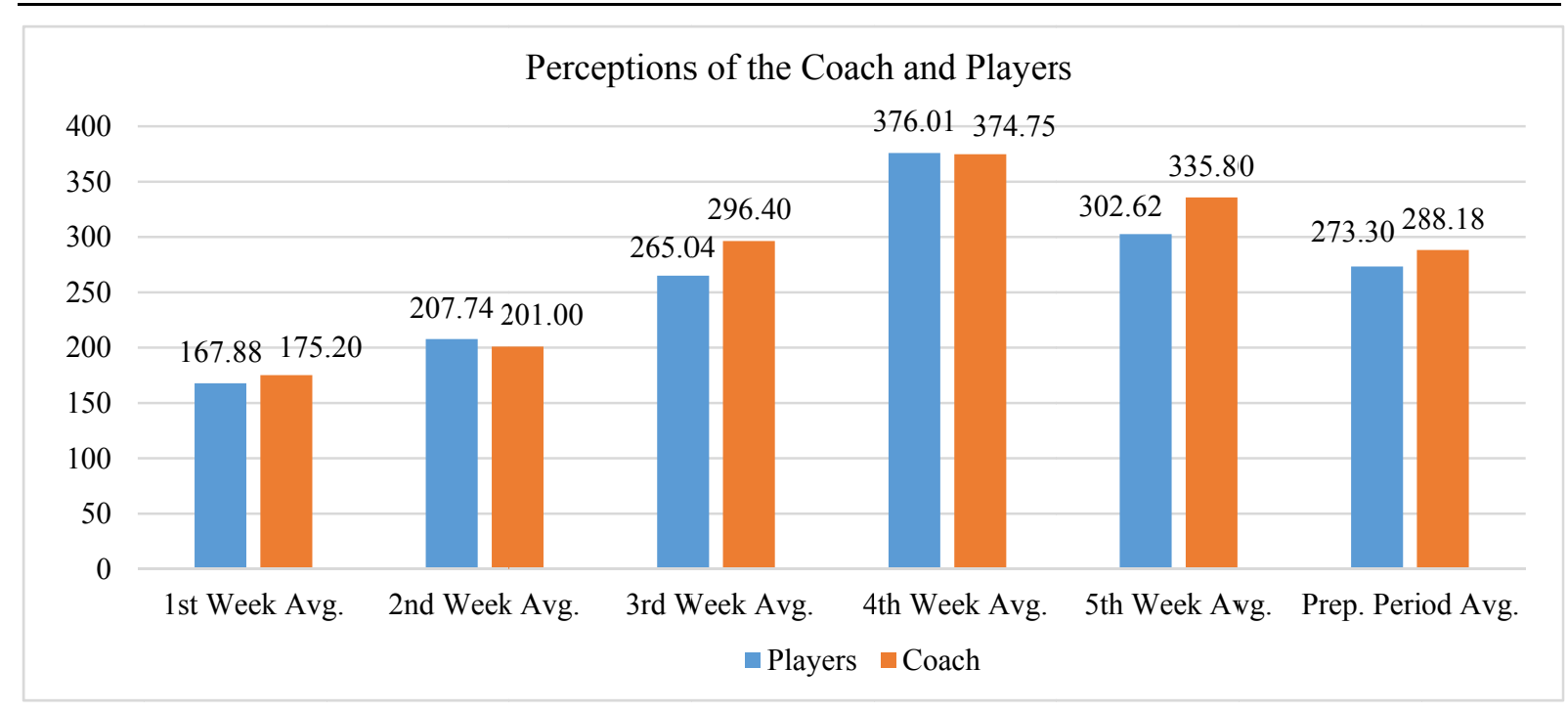

Figure 1. Comparison of rating of perceived exertion of coach and players

There was no statistical difference between the levels of difficulty perceived by the coach and the players during the preparation period. When Figure 1 is examined, it is determined that the average perception of the coach in the first, third, fifth week and preparation period is higher than the perceptions of the players.

\section{Discussion}

This research is one of the first studies to examine the Turkish elite young soccer players' perception of the load planned by their coaches based on various variables. In this research, the training load perceptions of the young elite soccer players based on their position, $\mathrm{VO}_{2}$ max and licensed years were examined and the soccer players' training load perceptions were compared.

The evaluation of the physical load by monitoring the training and match load is very important for training planning (Akubat et al., 2012). Previous studies have identified the relationship between the athletes' perceived load and training load (Coutts et al., 2003; Day at al., 2004; Impellizzeri et al., 2004; Wallace et al., 2009; Malone et al., 2017).

When the players' RPE values based on their positions were examined, no difference was found in the perceptions of the defenders and attackers in comparison with their perception of the preparation week. This shows that the perception of the team players does not create variability based on the position they play. It was observed that the perceptions of the defensive players had a tendency to increase compared to that of the offensive players during the preparation period. In a study supporting the findings of our study, the differences between the total body load of the defenders, midfielders and strikers and the RPE values of training periods were analyzed. No significant difference was reported in the RPE of the training based on the player's positions. However, it was noted that the midfielders had a tendency to decrease the RPE values when compared to the defenders and strikers (Gomez-Piriz et al., 2011). Moreover, our data are consistent with studies on volleyball 
players, which show that, regardless of the tactical position the players take, all positions agree on the perceived degree of difficulty among the coaches and players (Andrade et al., 2014). In another study (Jatene et al., 2019), a significant difference was detected between the RPE of soccer players in the goal-keeper position and the RPE of players in other positions. Moreover, a significant difference has been reported between the RPE values of players in center midfielder and wide midfielder positions.

As a result of analyses conducted, when the RPE values of the players based on the $\mathrm{VO}_{2}$ max values were examined, among the perceived mean scores of the third week, a significant difference was found between the group having the $\mathrm{VO}_{2}$ max value of " $48-50 \mathrm{ml} / \mathrm{kg} / \mathrm{min}$ " and the group having the $\mathrm{VO}_{2}$ max value of "50 and above" at the $\mathrm{p}<0.048$ level, in favor of the group with a $\mathrm{VO}_{2}$ max value of " $48-50 \mathrm{ml} / \mathrm{kg} / \mathrm{min}$ ". In the literature, there are no studies that correlate the RPE of soccer players based on the $\mathrm{VO}_{2}$ max values. Research is generally related to the soccer players' level of lactate, heart rate and perceived difficulty during training (Aslan et al., 2012, Fanchini et al., 2015, Kelly et al., 2016). In order to evaluate the external training load of soccer players, Jaspers et al. (2018) used machine learning and determined that distances covered above $20 \mathrm{~km} / \mathrm{h}(0.428)$ have less impact on the RPE values than distances covered at $15 \mathrm{~km} / \mathrm{h}(0.487)$ and $15-20 \mathrm{~km} / \mathrm{h}(0.507)$.

Following the t-test of the players, based on the licensed years varilable, a significant difference was detected between the 5-year and 6-year licensed players' first week perceptions at $\mathrm{p}<0.05$ level, the fifth week perceptions at $\mathrm{p}<0.04$ level and the preparation period perceptions at $\mathrm{p}<0.03$ level. It was determined that 5-year licensed players had higher perceptions in the first week, fifth week and preparation period compared to the players with a 6-year license. In their study, Malone et al. (2017) stated that soccer players with 0-1 year of training experience had higher RPE values and players with 7 years or more training experience had lower RPE values.

In one study, it was reported that the young elite players (U17 and U19) perceived their training load higher than the coach wanted (Brink et al., 2014). In this regard, we can assume that adult professional players may have better experience in determining their intended training load (Foster et al., 2001).

There was no statistical difference between the levels of difficulty perceived by the coach and the players during the preparation period. When Figure 1 is examined, it is determined that the average perception of the coach in the first, third, fifth week and preparation period is higher than the perceptions of the players. However, in general, it can be said that the coach has achieved the goal of gradually increasing training practice on his players in the preparation period plan and that there is a harmony between the players and the coach. These results are consistent with previous studies comparing the relationship between training programs planned by coaches and RPE values of athletes and swimmers. In these studies, strong correlations were detected between the intensity of training perceived by athletes and coaches (Foster et al., 2001; Wallace et al., 2009).

As a result, the positions of young soccer players did not make a difference for the rate of perceived exertion. However, years licensed and $\mathrm{VO}_{2}$ max values may be a distinguishing 
factor for training load perception. In addition, we can say that there is good harmony between the young players and their coach, and the coach provides a well-structured preparation period.

\section{References}

Akubat, I., Patel, E., Barrett, S., \& Abt, G. (2012). Methods of monitoring the training and match load and their relationship to changes in fitness in professional youth soccer players. $J$ Sports Sci, 30, 1473-1480. https://doi.org/10.1080/02640414.2012.712711

Andrade Nogueira, F. C. D., Nogueira, R. A., Coimbra, D. R., Miloski, B., Freitas, V. H. D., \& Bara Filho, M. (2014). Internal training load: perception of volleyball coaches and athletes. Revista Brasileira de Cineantropometria \& Desempenho Humano, 16(6), 638-647. https://doi.org/10.5007/1980-0037.2014v16n6p638

Aslan, A., Acikada, C., Güvenç, A., Gören, H., Hazir, T., \& Özkara, A. (2012). Metabolic demands of match performance in young soccer players. Journal of Sports Science \& Medicine, 11(1), 170.

Borg, G. A. (1982). Psychophysical bases of perceived exertion. Med Sci Sports Exerc, 14, 377-81. https://doi.org/10.1249/00005768-198205000-00012

Brink, M. S., Frencken, W. G., Jordet, G., \& Lemmink, K. A. (2014). Coaches' and players' perceptions of training dose: Not a perfect match. International Journal of Sports Physiology and Performance, 9(3), 497-502. https://doi.org/10.1123/ijspp.2013-0009

Coutts, A. J., Murphy, A., Pine, M., Reaburn, P., \& Impellizzeri, F. (2003). Validity of the session-RPE method for determining training load in team sport athletes. J Sci Med Sport, 6, 525-535. https://doi.org/10.1016/S1440-2440(03)80285-2

Day, M. L., McGuigan, M. R., Brice, G., \& Foster, C. (2004). Monitoring exercise intensity during resistance training using the session RPE scale. The Journal of Strength \& Conditioning Research, 18(2), 353-358. https://doi.org/10.1519/00124278-200405000-00027

Fanchini, M., Ghielmetti, R., Coutts, A. J., Schena, F., \& Impellizzeri, F. M. (2015). Effect of training-session intensity distribution on session rating of perceived exertion in soccer players. International Journal of Sports Physiology and Performance, 10(4), 426-430. https://doi.org/ 10.1123/ijspp.2014-0244

Foster, C., Florhaug, J. A., Franklin, J., Gottschall, L., Hrovatin, L. A., Parker, S., \& Dodge, C. (2001). A new approach to monitoring exercise training. The Journal of Strength \& Conditioning Research, 15(1), 109-115. https://doi.org/10.1519/00124278-200102000-00019

Foster, C., Hector, L. L., Welsh, R., Schrager, M., Green, M. A., \& Snyder, A. C. (1995). Effects of specific versus cross-training on running performance. European Journal of Applied Physiology and Occupational Physiology, 70(4), 367-372. https://doi.org/10.1007/ BF00865035

Gomez-Piriz, P. T., Jiménez-Reyes, P., \& Ruiz-Ruiz, C. (2011). Relation between total body 


\section{Macrothink Institute ${ }^{\prime \prime}$}

load and session rating of perceived exertion in professional soccer players. The Journal of Strength \& Conditioning Research, 25(8), 2100-2103. https://doi.org/10.1519/JSC.0b013e3 $181 \mathrm{fb} 4587$

Haddad, M., Chaouachi, A., Castagna, C., Wong, D. P., Behm, D. G., \& Chamari, K. (2011). The construct validity of session RPE during an intensive camp in young male Taekwondo athletes. International Journal of Sports Physiology and Performance, 6(2), 252-263. https://doi.org/10.1123/ijspp.6.2.252

Harrison, G. G. (1988). Skinfold thickness and measurement technique. Anthropometric Standardization Reference Manual (pp. 55-70).

Impellizzeri, F. M., Rampinini, E., Coutts, A. J., Sassi, A. L. D. O., \& Marcora, S. M. (2004). Use of RPE-based training load in soccer. Medicine \& Science in Sports \& Exercise, 36(6), 1042-1047. https://doi.org/10.1249/01.MSS.0000128199.23901.2F

Jaspers, A., De Beéck, T. O., Brink, M. S., Frencken, W. G. P., Staes, F., Davis, J. J., \& Helsen, W. F. (2018). Relationships Between the External and Internall Training Load in Professional Soccer: What Can We Learn From Machine Learning? International Journal of Sports Physiology and Performance, 13(5), 625-630. https://doi.org/10.1123/ijspp.2017-0299

Jatene, P., Pereira, G. B., Chaperuto, É. C., Fukushima, A. R., \& Doro, M. (2019). Training Sessions' RPE in Professional Football is Influenced by Playing Position. Journal of Physical Education and Sport, 19, 1398-1406. https://doi.org/10.7752/jpes.2019.s4203

Kelly, D. M., Strudwick, A. J., Atkinson, G., Drust, B., \& Gregson, W. (2016). The within-participant correlation between perception of effort and heart rate-based estimations of training load in elite soccer players. Journal of Sports Sciences, 34(14), 1328-1332. https://doi.org/10.1080/02640414.2016.1142669

Malone, S., Hughes, B., Mangan, S., Roe, M., \& Collins, K. (2017). The Factors that influence session-RPE in elite Gaelic football. The Journal of Strength \& Conditioning Research. https://doi.org/10.1519/JSC.0000000000002192

McGuigan, M. (2017). Monitoring training and performance in athletes. Human Kinetics.

Rodriguez-Marroyo, J. A., \& Antoñan, C. (2015). Validity of the session rating of perceived exertion for monitoring exercise demands in youth soccer players. Intermational Journal of Sports Physiology and Performance, 10(3), 404-407. https://doi.org/10.1123/ijspp.2014-0058

Wallace, L. K., Slattery, K. M., \& Coutts, A. J. (2009). The ecological validity and application of the session-RPE method for quantifying training loads in swimming. The Journal of Strength \& Conditioning Research, 23(1), 33-38. https://doi.org/10.1519/JSC.0b0 $13 \mathrm{e} 3181874512$ 


\section{Macrothink}

\section{Copyright Disclaimer}

Copyright for this article is retained by the author(s), with first publication rights granted to the journal.

This is an open-access article distributed under the terms and conditions of the Creative Commons Attribution license (http://creativecommons.org/licenses/by/3.0/). 